\title{
Sistemas educacionais comparados
}

\author{
MARIA TEREZA LEME FLEURY \\ - MARIA ISABEL LEME DE MATTOS
}

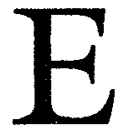

m um momento de profundos questionamentos sobre o sistema educacional brasileiro, suas lacunas e contradiçóes, a análise comparativa com o sistema educacional de outros países pode propiciar um quadro de referências interessante, para subsidiar o debate sobre políticas públicas neste setor.

Este texto objetiva comparar o sistema educacional paulista com o de outros países, em diferentes estágios de desenvolvimento, diferentes regimes políticos e raízes culturais diversas - são eles: Estados Unidos, França, Alemanha, Japão, Coréia e Cuba (1).

A comparação destes países com o Brasil e, mais especificamente com o Estado de São Paulo, foi fundamentada em dados e indicadores quantitativos e qualitativos. As principais fontes de dados consultados foram: Yearbook Statistical, UNESCO, os relatórios enviados pelos países para a Conferência Anual sobre Educação da UNESCO, de 1990, Anuários Estatísticos da FIBGE, CIE, MEC e publicaçóes sobre o tema.

Complementando a análise quantitativa, foi feito um estudo comparativo dos principais problemas diagnosticados nos países investigados, na última década, e as reformas e diretrizes adotadas (ou em estudo) para sua solução. Foram, assim, abordados tópicos relativos ao sistema de gestáo, qualidade e eficiência do ensino e qualificação do corpo docente.

Análise comparativa da estrutura de ensino, produção e eficiência dos sistemas de ensino

A premissa básica que orientou as políticas públicas de educaçáo nos países pesquisados, nas últimas décadas, foi: universalizaçáo e democratização do ensino. Esta premissa direcionou, também, o sistema educacional paulista, que estendeu a duração do ensino obrigatório e gratuito, ampliou a rede de escolas e o contingente de professores.

Entretanto, apesar dessa expansão quantitativa, o Estado de São Paulo situa-se, ainda, em um patamar abaixo dos padróes mundiais, como é possível observar no quadro abaixo: 


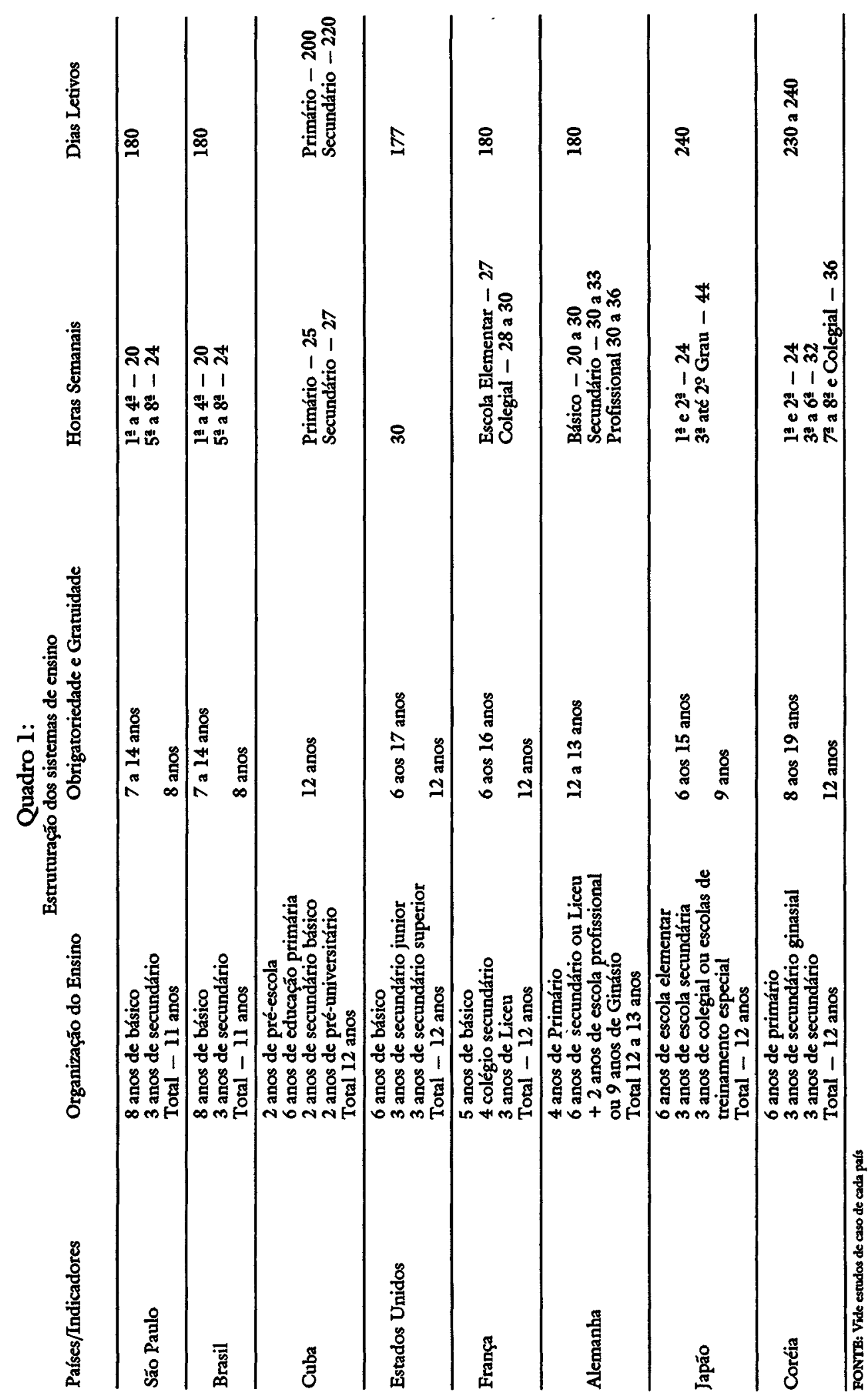


Entre os países pesquisados, o Brasil é o que apresenta a menor duração do ensino compulsório gratuito: 8 anos; a maioria dos países apresenta 12 anos (na Alemanha, os jovens que cursam o ginásio, que constitui o curso secundário por excelência, preparatório à universidade, devem estudar 13 anos). Entre os países desenvolvidos, o Japão é o que apresenta o menor número de anos de ensino compulsório gratuito: 9 anos. A partir do curso colegial, os pais começam a custear parte da educação. A entrada para o colegial é dificultada por exames seletivos; há poucos cursos colegiais públicos e o acesso é restrito. Assim mesmo, após a escola compulsória, cerca de $\mathbf{9 0 \%}$ dos jovens continuam a cursar algum tipo de colegial e $29 \%$ dos graduados no colegial entram para a universidade.

Todos os países pesquisados, com exceção do Brasil, diferenciam entre o curso primário e o secundário. $O$ curso primário tem a sua duração variando de 4 a 6 anos e uma carga horária que vai de 20 a 30 horas semanais, sendo que, na maioria dos países, a carga é de cerca de 25 horas/semana. O Brasil se encontra na média inferior, em termos de horas semanais: 20 para o primário e 24 para o secundário.

Estudos feitos nos Estados Unidos, comparando o sistema educacional americano com o japonês, mostram que a maior carga horária semanal, aliada à maior duração do ano letivo, resulta em, praticamente, mais um ano de educação compulsória no Japão.

As diferenças mais significativas se encontram na estruturação do curso secundário. Em todos os países pesquisados, a partir da metade do curso secundário, ou colegial, abrem-se as opçóes para os cursos profissionalizantes. Estes cursos fornecem ao formando, inclusive, um certificado, que lhe facilita o acesso ao mercado de trabalho.

Entretanto, por razóes de ordem mais cultural, justificam os especialistas em educação, como Lesourne (1988), os cursos profissionalizantes sáo sempre considerados como uma opção menor, destinados àqueles que não contam com recursos financeiros, sociais ou culturais para ingressar no ensino superior. A única exceção, no conjunto dos países pesquisados, é a Alemanha, país em que o ensino profissional goza de elevado status. Esta questão preocupa os países desenvolvidos e em desenvolvimento e muitos, como por exemplo a França, procuram criar passarelas que possibilitem aos estudantes transitarem entre os cursos.

No Brasil, durante a década de 70 (entre 1971 e 1982), o ensino profissionalizante foi obrigatório nas escolas públicas de segundo grau; em 1982, dispensou-se as escolas da obrigatoriedade da profissionali- 
zação, voltando-se a ênfase à formaçáo geral. O ensino profissional ficou a cargo das escolas técnicas e instituiçóes como SENAI/SENAC, existindo a possibilidade dos alunos formados nestes cursos ingressarem no nível superior.

A ênfase na expansão quantitativa do ensino tem sido acompanhada por críticas severas aos insucessos em termos de efetividade das estratégias educacionais; atrasos, abandono, repetências vão tomando forma cumulativa, a partir de lacunas mal resolvidas nos primeiros anos de escolaridade. Pergunta-se, então: A soluçáo é reduzir a escolaridade obrigatória? Multiplicar as passarelas e possibilidade de retorno ao sistema educacional? Esta pergunta é, particularmente, pertinente para países como o Brasil, que optaram por estruturar o curso de $1^{\circ}$ grau com 8 anos.

Observa-se, também, que apesar de todas as políticas de democratização do ensino, o meio social continua sendo um fator determinante para o sucesso escolar. Alguns países como o Japão partem da premissa de que a seletividade e $o$ afunilamento da pirâmide escolar, a partir do colegial, são determinados não só pelas características pessoais do estudante, mas também pelo nível econômico e cultural da família, capaz de arcar com as despesas educacionais, em termos de reforços e aulas adicionais.

Em países como o Brasil, a expansão do ensino público, se por um lado aumentou a oferta de vagas, por outro diminuiu a qualidade, reforçando indiretamente a rede privada, capaz de oferecer um ensino melhor. Com isto afunila-se a pirâmide na passagem para o curso secundário, mas também para o curso superior, principalmente nas melhores universidades públicas.

Esta questáo, de como conciliar a democratizaçáo do ensino com a qualidade e elevaçáo do nível de exigência, para acompanhar as mudanças aceleradas de nossos dias, preocupa também os educadores.

Com relaçáo à qualificaçáo exigida dos professores do primeiro segmento do primeiro grau, observa-se que no Brasil esta é inferior à dos países desenvolvidos e Coréia, comparável apenas a Cuba. Por outro lado, o salário dos professores brasileiros e mesmo paulistas é, também, bem menor do que dos países desenvolvidos, comparável apenas ao do professor coreano.

Quanto à taxa de escolarizaçáo, o quadro abaixo mostra como o conjunto de países amostrados supre satisfatoriamente a demanda de ensino para o $1^{\circ}$ grau, com exceçáo do Brasil, que atende apenas a $83 \%$ 
da população escolarizável. Com relação aos dados de cobertura, observa-se que o sistema educacional paulista destaca-se do País, atingindo uma taxa real de escolarizaçăo de $90 \%$, a menor entre os casos amostrados, mas próxima do ideal, considerado entre 95 e $97 \%$

\section{Quadro 2:}

Taxa de escolarizaçáo

\begin{tabular}{l|r|c|c|c}
\hline \multirow{2}{*}{ PAÍs/GRAU } & \multicolumn{2}{|c|}{1 \% GRAU } & \multicolumn{2}{c}{ 20 GRAU } \\
\cline { 2 - 5 } & \multicolumn{1}{|c|}{ Bruta } & Líquida & Bruta & Líquida \\
\hline São Paulo (87/88) & $105,0 \%$ & $90,0 \%$ & - & $25,0 \%$ \\
Brasil (1983) & $103,0 \%$ & $83,0 \%$ & $35,0 \%$ & $14,0 \%$ \\
Cuba (1984) & $106,0 \%$ & $95,0 \%$ & $75,0 \%$ & - \\
Est. Unidos (1984) & $101,0 \%$ & $96,0 \%$ & $95,0 \%$ & $85,0 \%$ \\
França (1982) & $108,0 \%$ & - & $88,0 \%$ & $81,0 \%$ \\
Alemanha (1983) & $99,0 \%$ & - & $74,0 \%$ & - \\
Japáo (1984) & $100,0 \%$ & $100,0 \%$ & $95,0 \%$ & $95,0 \%$ \\
Coréia (1985) & $96,0 \%$ & $93,0 \%$ & $94,0 \%$ & - \\
\hline
\end{tabular}

FONTE: São Paulo: Educação em São Paulo, uma análise regional. SEADE (Fundaçăo Sistema Estadual de Análise de Dados). Demais sistemas: Anuário da UNESCO.

Quanto ao ensino de $2^{\circ}$ grau, a situação é bem mais problemática, tanto em termos brasileiros, cuja taxa de escolarizaçáo líquida é de $14 \%$, como paulista, cuja taxa é de $25 \%$. Com relação aos países amostrados, observa-se que a universalizaçáo do ensino secundário foi alcançada apenas nos países orientais (Japão e Coréia). Os Estados Unidos se aproximavam deste objetivo em 1984, com $85 \%$ de cobertura, taxa semelhante à da França em 1981.

No que se refere às despesas com educaçáo, observa-se que tanto a média brasileira como a paulista situam-se em patamares bastante inferiores aos dos demais países. Mesmo a Coréia, onde a tendência dominante é para o ensino de massa, com maior número de alunos por professor e com menores salários docentes, apresenta uma taxa de despesa por aluno superior à paulista. 


\section{Quadro 3:}

Despesas com educação por aluno/ano

matriculado no sistema.

\begin{tabular}{l|c}
\hline & Em US\$ \\
\hline São Paulo $\left(^{*}\right)$ & $249,0\left(^{*}\right)$ \\
Brasil & 148,0 \\
Cuba & 709,1 \\
EUA & $3.865,4$ \\
França & $3.417,5$ \\
Alemanha & $2.131,1$ \\
Japáo & $1.757,7$ \\
Coréia & 362,6 \\
\hline
\end{tabular}

$\left(^{*}\right)$ exclusivamente rede estadual

FONTE: Para São Paulo: Balanço Geral das Contas do Estado. Para os demais paises: Anuário UNESCO,

E, finalmente, os indicadores de efetividade do sistema, em termos de evasão e repetência, não são animadores para o caso brasileiro e paulista. Neste item, foi possível realizar comparaçóes parciais com outros países, pela falta de dados disponíveis.

\section{Quadro 4:}

Distribuiçáo dos indicadores de desempenho (evasăo e repetência) pelos países amostrados

\begin{tabular}{l|c|c}
\hline & Evasão & Repetência \\
\hline São Paulo (86) & $\begin{array}{l}\text { 19 GRAU }=9,6 \% \\
\text { 20 GRAU }=21,0 \%\end{array}$ & $\begin{array}{l}\text { 19 GRAU }=18,6 \% \\
2 \% \text { GRAU }=11,12 \%\end{array}$ \\
\hline Brasil (82) & - & $21,0 \%$ \\
Cuba (84) & - & $4,0 \%$ \\
Estados Unidos (87) & - & $6,5 \%$ \\
França (79) & - & $9,0 \%$ \\
Alemanha (83) & - & $2,0 \%$ \\
Japão & - & - \\
Coréia & - & - \\
\hline
\end{tabular}

PONTE: Săo Paulo: Educaçăo em Săo Paulo, uma análise regional. SEADE (Fundaçāo Sistema Estadual de Análise de Dados). Demais sistemas: Anuários da UNESCO. 
Observa-se, neste quadro, que os índices de repetência do Brasil e de São Paulo sáo bastante altos, quando comparados com qualquer país da amostra. Embora não tenhamos obtido dados sobre os países orientais, é sabido que o sistema japonês praticamente exclui a possibilidade de retençáo e que o sistema coreano é considerado de grande sucesso quanto às metas quantitativas.

\section{Análise comparativa das principais diretrizes, políticas e reformas dos sistemas educacionais estudados e os resultados alcançados}

A partir dos estudos de caso realizados e da análise comparativa de indicadores quantitativos e qualitativos, procurou-se neste item discutir as principais políticas adotadas com relação ao sistema educacional de cada país, expressas ou não em reformas e diretrizes, e seus resultados e conseqüências.

Levando-se em consideração que, nas últimas décadas, todos os países pesquisados partiram de uma premissa comum: universalização e democratizaçáo do ensino, verificou-se que a adoçăo de diferentes estratégias de gestão do sistema, de priorização dos elementos fundamentais, conduziram a resultados diversos.

A adoção destas estratégias pode ser explicada por raízes históricas, ou por condicionantes políticas, econômicas, sociais e conjunturais. Entre estas, destacaríamos o mercado de trabalho, que, atribuindo valores às ocupaçóes e aos diferentes títulos e níveis de escolaridade, acaba por influenciar todo o sistema.

Tomando como ponto de partida a estratégia adotada de gestão do sistema (mais ou menos centralizado), seráo analisadas as várias dimensóes relativas à estrutura do ensino (duraçáo, carga, curriculum), ao processo (incluindo a situaçăo do corpo docente) e aos resultados alcançados.

Um dos principais aspectos definidores da administração do sistema como mais ou menos centralizados é o grau de concentração de poder do governo central nas questốes relativas à educaçăo.

No Japáo, cujo modelo pode ser considerado dos mais centralizados, o Ministério da Educaçáo define as matérias que comporáo o currículo, o número de horas/aula e a duração do ano letivo nas escolas primárias e secundárias, procede à seleção do material didático e ao fornecimento deste às escolas primárias e secundárias inferiores, provê assistência financeira aos estados e municipalidades, regulamenta e pro- 
vê supervisão geral às instituições privadas. Este poder é partilhado com as instâncias locais, províncias e municípios, inclusive os gastos com educação. Este sistema é considerado rígido; um exemplo freqüientemente citado da falta de flexibilidade é o fato do aluno, no ensino compulsório, náo poder optar por uma escola fora do distrito domiciliar. Por outro lado, a administraçáo dispóe de recursos eficientes para garantir uma boa qualidade de ensino para todos, como por exemplo, a rotatividade compulsória dos professores pelas escolas da regiáo, o que dificulta a criaçáo de centros de excelência, localizados em geral nas zonas urbanas mais afluentes.

Vale ressaltar que os professores, enquanto categoria profissional, reagem a este tipo de administraçáo; as suas reivindicaçóes, relacionam-se, em sua maioria, à maior autonomia da própria prática pedagógica, como por exemplo:

- maior autonomia das escolas em relação ao poder central;

- maior liberdade para escrever ou escolher os livros didáticos;

- tornar a educação mais centrada no aluno.

Estas reivindicações representam não só um desejo de maior autonomia para realizar o próprio trabalho, mas, ainda, uma crítica ao resultado deste mesmo trabalho - $o$ aluno japonês que tem um alto desempenho em avaliaçóes de conhecimento internacionais, mas que é visto pelas tendências liberais da sociedade japonesa como muito despreparado para enfrentar um futuro que se afigura mais cheio de mudanças e incertezas do que o passado, quando do reerguimento de uma nação derrotada no pós-guerra, para o qual foi talhado o modelo de educação japonesa. Como se observam muitas semelhanças desta problemática com a vivida na Coréia, analisaremos esta questão nos dois países.

A centralização da administração da educação na Coréia é definida pelos seguintes aspectos: o Ministério da Educação provê assistência financeira (as verbas federais constituem o maior componente do orçamento das escolas) e assessoria em termos das políticas educacionais; produção e supervisão do material didático, principalmente no nível da escola elementar; decisóes sobre o terceiro grau, tal como valor das anuidades; qualificação do corpo docente, currículo, e requisitos para a graduação.

Também neste país a educação tem sofrido críticas semelhantes às do Japáo, no que diz respeito à qualidade do ensino em termos do seu alunato, que também mostra um alto desempenho em testes objetivos realizados em avaliações internacionais, mas apresenta deficiências quan- 
to a um pensamento mais flexível e criativo, demandado em solução de problemas.

Tem-se considerado que uma das conseqüências da centralizaçáo da educaçáo, tanto no Japão como na Coréia, seria a sua excessiva padronização, principalmente nos níveis mais elementares de ensino. Se, por um lado, tal padronizaçáo representou um esforço no sentido da democratizaçáo e universalizaçáo do ensino, provendo-se o acesso de todos à educaçăo e a igualdade de qualidade no esforço de reconstruçáo do pós-guerra, por outro, tal política, aliada às condiçóes econômicas dos dois países de racionalizaçáo das despesas, levou a um excessivo número de alunos por classe, no acesso mais limitado aos níveis de instruçáo superiores, resultando em um tipo de instruçáo limitada à transmissão de conhecimento. Seu produto é um aluno com uma boa bagagem de informaçóes e capacidade para responder a testes, mas pouco autónomo para resolver problemas e adaptar-se de modo criativo a mudanças.

No Japão, os esforços para modificar tal situação atacam, a nosso ver, mais os sintomas do que as causas. Tem-se procurado diversificar o ensino tradicional, baseado primordialmente na transmissão de informação e na avaliaçáo da sua correta retenção pelo aluno, para um ensino mais renovado, no sentido de maior atençáo à individualidade daquele, em termos de suas aptidóes, gostos e habilidades. Também a primeira triagem para a universidade, cujo acesso limitado determinava muito o tipo de ensino propiciado nas escolas secundárias, foi modificada no sentido de favorecer a seleção baseada em critérios mais individualizados do que somente o desempenho em testes.

Já a Coréia realizou, a nosso ver, um diagnóstico mais realista, verificando que estes problemas resultavam de uma administração que induzia as unidades escolares à passividade e à irresponsabilidade pelos resultados obtidos. Neste sentido, tem procurado modificar o sistema de modo a atender três princípios básicos que deverão nortear as atividades educativas em todos os níveis: independência, profissionalismo e iniciativa comum. A composição dos órgáos deliberativos e executivos passou a ser feita por eleição, substituindó o sistema de indicaçóes e as unidades escolares dispóem, atualmente, de maior autonomia financeira, pela criação de um imposto local que garantirá a subsistência das escolas naquela regiáo, e também administrativa, pelo encorajamento à administraçáo por objetivos, visando estimular a avaliação dos resultados e o profissionalismo dos professores. Foi, ainda, criado um fundo para melhorar as condiçóes educacionais, como diminuiçáo do número de alunos por classe, escolas melhor dimensionadas e menor sobrecarga de trabalho para os professores. Na parte pedagógica, a produçáo de 
material didático está sendo reavaliada a fim de ser substituída por livros produzidos pela livre iniciativa, no sentido de diversificar os programas educacionais. Novos métodos de ensino estão sendo pesquisados para melhor desenvolver a individualidade do aluno, o pensamento crítico, raciocínio lógico e criatividade na soluçáo de problemas, tolhidos pelo ensino uniforme que já mencionamos anteriormente.

Estas mudanças não têm se limitado aos níveis elementares de ensino: também o terceiro grau foi beneficiado com uma maior liberdade - o Ministério não interfere mais nos assuntos acadêmicos como a organizaçăo e operacionalizaçáo dos currículos, e também dispensou da sua aprovação a composição dos órgáos colegiados e reitores. Além disso, as instituiçóes de ensino gozam atualmente de maior liberdade na cobrança de anuidades.

Algumas mudanças de ordem qualitativa são dignas de nota como a ênfase na reflexão sobre o trabalho futuro, através de orientação vocacional e na educação para o trabalho. Tanto na Coréia como no Japão, o diploma de nível superior é muito valorizado porque garante os melhores empregos. O difícil acesso ao ensino superior confere aos seus graduados um certificado informal de dedicação pessoal, de disciplina e outros traços de caráter valorizados na iniciativa privada dos dois países. Neste sentido, o afunilamento educacional começa no curso secundário, na medida em que o valor de uma escola é julgado pelo número de candidatos colocados na universidade. Os cursos vocacionais neste nível são julgados, justificadamente, como uma opçáo menor para aqueles que não conseguiram uma vaga nas instituiçóes mais prestigiadas, independentemente das suas aptidóes e gostos pessoais. A orientação dos jovens para uma reflexão sobre o trabalho futuro na Coréia e no Japão, a tentativa de realizar avaliaçóes que considerem estes aspectos, inclusive em entrevistas no processo de seleção, representam um esforço no sentido de uma adaptação do sistema ao indivíduo. Por outro lado, a consciência de que o secundário c o conteúdo abordado se restringem a um preparo para um exame de seleção, deixando de lado a formação do indivíduo como um todo, tem preocupado as autoridades educacionais no sentido do comprometimento futuro da nação, não só no plano econômico mas, também, moral.

A França também tem uma administração que pode ser considerada muito centralizada e merece uma análise separada, em função de algumas peculiaridades, não tanto na gestão do sistema, que em termos de controle do Estado é semelhante ao Japáo e Coréia, mas pela forma que a cultura vem trabalhando a questáo e as reflexóes que podem contribuir 
para o esclarecimento deste problema do papel do Estado na gestão da educaçăo.

O poder central garante seu controle sobre o sistema através dos seguintes mecanismos: o Estado é responsável pela gratuidade do ensino; a manutençáo total das escolas públicas e parcial das privadas sob contrato; o provimento do material escolar; o recrutamento, formaçáo e gestáo de pessoal e estabelecimento do currículo. As medidas no sentido da descentralização foram: transferência para as autoridades regionais da responsabilidade da formação profissional, planejamento escolar e transporte dos alunos.

Estas medidas são consideradas insuficientes em virtude do gigantismo do sistema, da burocracia complexa, que não cessaram de crescer, mesmo depois da descentralização ter sido iniciada. Em conseqüência, persiste a ausência de coordenação entre as autoridades e os serviços, 0 excesso de regulamentaçáo por parte do governo central, que ainda encontra respaldo nas autoridades regionais, que acreditam que a descentralizaçáo deve ser de inciativa da primeira instância. Este tipo de mentalidade, reflete Lesourne (1988), demonstra que a problemática da gestáo do sistema na França não se reduz a uma mera transferência de responsabilidade da administraçáo central para a regional mas, sim, de descentralização do poder, que pede uma análise mais profunda $e$ acurada do processo a ser realizado. A seu ver, uma descentralização baseada no modelo alemão, do qual trataremos mais adiante, não seria factível na França, tendo em vista que o grande número de regióes e a diversidade existentes entre elas gerariam incoerências, com as quais as autoridades regionais francesas, diferentes das dos estados alemães, não teriam condiçóes de lidar. De acordo com a proposta deste autor, o processo de reforma da administração francesa deve iniciar por um estudo das grandes funçóes do Ministério, seguida por uma análise mais detalhada das funçóes e procedimentos de cada serviço do mesmo, para então se decidir como serão assumidos pelas várias instâncias. A tranferência de responsabilidades deve ser feita gradativamente, após o treinamento do pessoal regional que as assumirá.

Verificamos, portanto, que a questăo da descentralização de um sistema educacional náo deve se limitar a uma mera transferência de responsabilidades, sob pena de se reproduzirem em menor escala os mesmos velhos problemas que levaram à tentativa de mudança. Devemos considerar ainda que as revisóes dos modelos ocorreram tanto em gestóes centralizadas como descentralizadas, em funçáo de problemas ocorridos, ou até mesmo pela previsão de que estes poderiam ocorrer no futuro, como fizeram Japão e Coréia. 
Nesta perspectiva, consideramos com cautela a ausência de qualquer falha relacionada ao tipo de administraçáo do sistema educacional cubano, que também pode ser considerada bastante centralizada. Cabem ao Ministério da Educação as funçóes normativa e deliberativa e as executivas, às províncias. No que diz respeito ao aspecto quantitativo, consideramos que tal ausência de crítica se justifica, tendo em vista que os índices de atendimento à populaçáo em idade escolar foram da ordem de $100 \%$ entre 1988 e 1990, sendo ainda baixíssimos os índices de evasão, da ordem de $3 \%$ apenas, indicando uma real universalização do ensino no país. Náo obstante, a literatura consultada, quando aborda a questão de desenvolvimentos futuros, se atém a aperfeiçoamentos e promoção de aspectos, que, tratados de forma genérica, nâo permitem uma visão do leitor sobre resultados alcançados, em termos de competências do alunato, adequações necessárias, etc.

Neste sentido, o exame dos sistemas descentralizados, principalmente o modelo americano, acrescenta mais dados a esta análise do papel das diversas instâncias do Estado na gestão da educação e suas consequiências para a qualidade do ensino.

A crise do sistema educacional americano não é recente, data da década de 60. Porém, a consciência desta crise despertou bem mais tarde, quando o país começou a perder sua liderança no mercado mundial, ao mesmo tempo em que cresciam os problemas de natureza social, como violência escolar e uso de drogas. Em 1983, foi publicado o documento Uma Nafão em Risco, que após um estudo extensivo classificou a educaçáo americana como mediocre, clamando, ao mesmo tempo, por uma volta aos antigos padróes de excelência em termos de oferta, expectativas e desempenho.

Citaremos alguns problemas dignos de nota, apontados no documento, que evidenciam como a total autonomia dos estados, no que concerne à administração do sistema escolar, levou a uma situação que poderia ser definida como um laissez faire irresponsável.

Na parte pedagógica, verificou-se que a liberdade dos alunos de montar o próprio currículo nas escolas redundou em um elenco de disciplinas tão diluído a ponto de não conter mais um objetivo central. Além disso, a ênfase excessiva no desenvolvimento da personalidade e da individualidade levou à criação de disciplinas que pouco contribuem para a formação acadêmica ou profissional do indivíduo. A maioria das empresas que utilizam a mão-de-obra egressa do secundário tem aumentado suas despesas com treinamento, de modo a suprir deficiências consideradas básicas. A proposta, seguida em alguns estados, foi a exigência 
do cumprimento de um currículo mínimo com maior carga horária nas disciplinas básicas como Inglês, Matemática, Ciências e Estudos Sociais. Também foi proposto que a instruçáo escolar enfatizasse a aprendizagem de conhecimentos de modo mais profundo do que extensivo, e procurasse desenvolver o raciocínio organizado nos alunos. Além disso, verificou-se que a educação livre de valores, praticada até então, em nada contribuía para a solução dos problemas sociais, como consumo de drogas e violência escolar. Foi proposto que as escolas voltassem a enfatizar a educação moral, o que foi seguido por vários estados. Para facilitar estas mudanças, tentou-se aumentar o número de horas-aula e o ano letivo, para 220 dias, o que năo foi colocado em prática, em função da forte oposiçăo dos sindicatos de professores.

$\mathrm{Na}$ questão da administraçăo, redefiniram-se algumas responsabilidades e atribuiçóes:

Ao governo federal, ficou atribuído o papel de colher e disseminar informaçóes importantes e estabelecer objetivos, de acordo com os problemas diagnosticados no sistema. Aos governos estatuais, ficou delegada maior participação no custeio da educação, a fim de equalizar a situação financeira dos distritos escolares, a supervisão da contabilidade destes, supervisáo do desempenho escolar e acompanhamento mais atento das seguintes questôes: treinamento e qualificaçáo de professores, administraçáo e liderança escolar, instalações escolares, envolvimento das famílias com a escola. Foi, ainda, sugerido que estas últimas pudessem escolher livremente as escolas, mesmo que fora do seu distrito domiciliar, a fim de aumentar a competitividade entre estas. Esta sugestáo encontrou fortes resistências por parte dos distritos, que consideraram que esta medida seria injusta para aquelas mais pobres, que enfrentariam ainda problemas de ordem prática, como a questáo do transporte dos alunos para outro distrito.

Entretanto, algumas medidas no sentido de estimular a competiçáo entre as escolas têm sido colocadas em prática pelo governo federal, como: avaliar rotineiramente os estudantes nas idades de 9, 13 e 17 anos, nas 3로 $7^{a} s$ e $11^{a} s$ séries.

As escolas que se destacam pelo desempenho de seus alunos nestas avaliaçōes são premiadas com o reconhecimento público da sua excelência. Em alguns estados, tem-se tomado medidas mais coercitivas com relação aos seus distritos que não cumprem as exigências: é declarada falência acadêmica do distrito que passa a ficar sob a intervençáo do Estado. Outra medida que tem sido implantada em muitos estados é o encorajamento da autonomia das unidades escolares com relação ao es- 
tabelecimento de objetivos e a mensuração objetiva da sua consecução. Neste sentido, tem sido considerado essencial que os diretores das unidades exerçam um papel de liderança neste processo, o que não ocorria anteriormente, em funçáo da formaçáo e critérios de seleçáo destes profissionais. Na maioria dos estados, este posto era alcançado mais em função do número de anos de serviço e cursos do que a aptidáo propriamente dita. Além disso, verificou-se que os critérios de seleçăo usados na maioria dos distritos eram, também, de ordem política. Atualmente, muitos estados estabeleceram critérios mais rigorosos de seleção.

Considerando os problemas enfrentados pela educaçáo americana, é surprendente a ausência de problemas relacionados à administraçáo do sistema educacional na Alemanha. $O$ tipo de gestão praticada pode ser considerado dos mais descentralizados pelo papel apenas legislativo desempenhado pelo governo federal, cabendo aos estados total responsabilidade pela administração da educaçăo. Esta total autonomia gerou uma grande diversidade de sistemas educacionais entre várias regióes, 0 que, entretanto, $\epsilon$ considerado vantajoso para o enfrentamento de mudanças e problemas pelo sistema, que pode responder a estes de forma mais rápida e flexível do que seria possível para aqueles cujas decisóes envolvem um número maior de instâncias. $O$ único problema apontado para a diversidade existente relaciona-se à equivalência de certificados $e$ diplomas universitários. Admitindo-se que sejam estas as únicas dificuldades decorrentes da descentralizaçáo do sistema educacional alemão, não devemos nos esquecer que o país, enquanto nação livre e soberana, resulta da uniáo de ducados e principados autonômos, com uma estrutura educacional bem consolidada há muito tempo. A centralização da administraçáo educacional representaria, provavelmente, a dissolução de uma estrutura já organizada e integrada, cuja atuaçáo poderia ser comprometida.

A conclusáo que esta análise favorece é que a gestão de um sistema educacional é complexa não só porque depende da forma que o Estado administra todas as questóes relativas ao desenvolvimento da naçăo, da história desta administraçáo, da cultura que determina e que permanece como resultado desta mas, principalmente, pela provisoriedade dos modelos decorrente das mudanças aceleradas que vivemos em todos os planos. Neste sentido, a soluçáo parece ser a consciência coletiva de que os modelos adotados sáo provisórios na medida em que atendem a determinadas necessidades da nação em uma dada conjuntura, e que é necessário estar sempre avaliando a adequação do modelo, revisando e modificando os aspectos que podem contribuir para o seu aperfeiçoamento. 
Como bem lembra Lesourne (1988), as medidas que estamos implantando hoje teráo conseqüências ainda no ano 2020 ou 2040, quando os alunos dos professores que estamos formando estarão ingressando no mercado de trabalho.

Considerando a questão sob este prisma, da longevidade das açóes e da sua provisoriedade frente a mudanças no cenário mundial, verificamos como é importante, para o sistema, a existência da formaçăo dos professores. Vamos analisar como esta questão vem sendo resolvida nos países estudados.

Um fenômeno comum a todos os países foi a perda de qualidade do corpo docente em vista da explosão educacional ocorrida nas décadas de 60 e 70, aumentando a demanda e baixando as exigências para o recrutamento e qualificação dos professores. No Japão, onde existem dois tipos de certificado, de primeira classe para os professores com formaçáo mais longa e especializada e de segunda classe, para aqueles que comumente vâo lecionar nos níveis mais elementares, válidos em todo o território nacional e por toda a vida, a soluçăo encontrada foi tornar a profissáo mais atrativa pela sua melhor remuneraçáo, comparada a outras profissóes com o mesmo grau de escolaridade. Além disso, os professores gozam de alto prestígio na sociedade japonesa. A formaçáo em serviço inclui viagens ao exterior, treinamentos periódicos em centros regionais e realizaçáo de pesquisas em escolas experimentais.

O tipo de qualificação docente na Coréia é semelhante à do Japão - formaçáo universitária básica para profissionais de 10 grau e mais longa e especializada para profissionais de $2^{\circ}$ grau. Entretanto, os salários são considerados baixos e o trabalho árduo, em função do número elevado de alunos por classe e da carga horária, fazendo com que a carreira docente não tenha o mesmo atrativo que no Japáo. Uma soluçáo tentada foi procurar atrair, para a profissáo docente, alunos de $3^{\circ} \mathrm{grau}$ com bolsas de estudo e isençáo de taxas, sob a condiçáo de servirem como professores depois da graduaçăo. Este tipo de política está sendo revisado por não ter produzido os resultados esperados. Uma conclusáo importante foi que os professores, descontentes com a baixa remuneraçáo, náo se percebem como profissionais em uma perspectiva ampla e, neste sentido, se comprometem pouco com o seu trabalho e aperfeiçoamento docente. Embora tenha melhorado recentemente, a remuneração docente ainda é baixa comparada a outras profissóes com o mesmo grau de escolaridade. Os cursos de aperfeiçoamento docente mais procurados sáo aqueles que levam à promoçáo na carreira, em detrimento dos destinados à adaptaçáo a mudanças ou ampliaçáo do conhecimento. 
Os professores franceses também estão descontentes com a perda de prestígio causada pela menor remuneraçáo e à maior dificuldade em exercer a atuação docente nos últimos vinte anos. $O$ profissional não é mais visto como o detentor de conhecimentos preciosos a serem transmitidos a seus alunos. Sofre concorrência dos meios de comunicação mais abundantes, que, inclusive, mostram a provisoriedade destes conhecimentos. As disciplinas, em função destas mudanças e da introdução de uma grande diversidade de recursos pedagógicos, perderam sua identidade intrínseca. A prática pedagógica tende a se tornar cada vez menos uma transmissáo de um corpo de conhecimentos bem integrado para, cada vez mais, uma ordenação aproximativa de conteúdos, sujeitos à revisão fortuita. Além disso, os professores vêm enfrentando uma crise de identidade com a progressiva descaracterização dos estabelecimentos de ensino, mais voltados para a educaçáo em massa do que para as práticas artesanais passadas. Espera-se que o professor atue como um orientador de jovens e que, ao mesmo tempo, exerça autoridade sobre eles. Estas constatações ainda não encontraram uma boa solução na educação francesa, mas mostram alguns aspectos importantes a serem considerados na formação de futuros profissionais.

Uma das conseqüências de alta descentralização de sistema foi justamente a qualificaçăo docente nos Estados Unidos - além das especificaçóes para o exercício docente variarem de estado para estado, também a composiçáo dos currículos variava nas instituiçóes de ensino superior. Verificou-se que uma grande proporção de graduados havia cursado maior quantidade de disciplinas relativas à prática pedagógica do que relacionada aos conhecimentos específicos da disciplina de habilitaçáo. $O$ único estado que realizava uma avaliação de conhecimentos, por ocasião da obtenção do certificado, era a Carolina do Norte, prática que está sendo adotada em vários estados atualmente, junto com uma exigência de créditos mais específica quanto às disciplinas cursadas. Outra medida que está sendo implantada, no sentido de melhoria da qualificaçáo dos futuros docentes, é o sistema de credenciamento das instituiçóes de ensino superior após avaliaçóes periódicas. Com relação ao aperfeiçoamento docente, têm-se procurado incentivos dos mais variados, além dos cursos e materiais didáticos já disponíveis nos distritos escolares: pagamento de anuidade em cursos de pós-graduação, aumento de salário, exigências para recontratação, etc.

Uma das preocupações atuais na Alemanha é a previsão de um excedente de professores a partir de meados da década de 90 , em funçáo da diminuição da população, causada pela queda da natalidade. Embora a tendência já esteja se estabilizando nos últimos anos, seus efeitos já 
podem ser sentidos nas escolas elementares, onde há um menor número de alunos por classe. Como a profissáo é muito bem remunerada no país pode-se prever maior competiçáo pelas vagas que restarem. Além disso, o sistema de ensino alemão mostra-se muito voltado para o trabalho na indústria, quando a tendência futura é a progressiva automaçáo neste setor e a maior demanda por profissionais para o setor secundário. Neste sentido, é provável que as já rigorosas exigências para o exercício do magistério, quatro a cinco anos de curso superior mais um ano e meio de experiência prática estagiando em escolas, tornem-se ainda mais restritivas. A formação em serviço também é bastante exigente. Todos os professores devem passar periodicamente por um determinado número de horas de cursos para se atualizarem nos últimos avanços no seu campo de atuaçáo. Alguns incentivos são dados como licença remunerada para cursos de pós-graduaçáo, pagamento das despesas quando o curso exige deslocamento para outra localidade, e participação em projetos pilotos para investigação de problemas em áreas de interesse futuro como novas tecnologias de ensino, educaçáo ambiental, etc.

Concluímos, portanto, após o exame dos diversos sistemas educacionais, que as revisóes feitas nos modelos de gestão foram no sentido de um maior equilíbrio de responsabilidades, direitos e deveres das diversas instâncias envolvidas no processo educacional. Como mostram os exemplos americano e coreano, nem a total autonomia nem a dependência estrita do poder central conduzem a bons resultados. Ao que tudo indica, deve ser atribuída a esta instância um poder mais normativo do que executivo, não só pela sua distância da realidade do cotidiano escolar mas, principalmente, pela perspectiva mais ampla dos problemas e desafios a serem enfrentados a médio e longo prazo pela naçáo. Por outro lado, a unidade escolar vivencia mais de perto as aspiraçóes e os problemas da sua comunidade e pode, assim, responder de forma mais ágil e adequada do que as instâncias administrativas. Neste sentido, nos parece essencial que a unidade escolar disponha de autonomia para colocar seus objetivos e administrar a sua consecuçáo. Só assim, pode-se esperar que atue com profissionalismo e responsabilidade com relaçăo à qualidade do ensino proporcionado ao seu alunato. Um aspecto essencial neste processo é o papel desempenhado pelo diretor e pelo corpo docente. A qualificação destes profissionais deve ser objeto de cuidadosa consideraçáo, assim como a carreira docente, de modo a atrair pessoal realmente qualificado e motivado que possa garantir um ensino de boa qualidade.

\section{Conclusão}

As conclusóes a partir da comparaçáo do Brasil com outros países 
nos são pouco lisonjeiras. Como os demais, procurou-se universalizar e democratizar a educação pela expansáo de estabelecimentos e vagas na escola pública. Também, como nos demais países, a qualidade foi sacrificada em favor da quantidade. Em outras palavras, facilitou-se $o$ acesso das camadas menos favorecidas à educação, mas os investimentos não foram aumentados proporcionalmente. Vimos que o Brasil é o país, entre os estudados, que menos investe em educação. Vimos, ainda, que refletindo esta tendência, o salário dos professores brasileiros é menor que nos demais países, comparável apenas ao dos professores coreanos. A qualificaçăo exigida destes profissionais também só é comparável à de Cuba. Além disso, nossos alunos são os que passam o menor tempo na escola, tanto em anos de escolarização compulsória como em carga horária semanal.

Nesta perspectiva, não é de se admirar que os indicadores de efetividade do sistema sejam os piores entre os países que divulgam estes dados.

A situação no Estado de São Paulo é um pouco mais alentadora que no resto do Brasil: os índices de cobertura aproximam-se, em certas regiōes administrativas, do ideal de $95 \%$, os indicadores de efetividade do sistema, um pouco superiores à média brasileira, mas ainda assim, alarmantes. Verifica-se, portanto, que o problema da educação em São Paulo não é de oferta e, sim, de qualidade, premissa que orientou os programas de democratizaçăo de ensino das duas últimas gestóes Ciclo Básico e Jornada Única.

Entretanto, estes programas náo lograram os resultados esperados, diminuição de repetência e evasáo em função da administração do sistema e da falta de articulação destes com as séries seguintes.

Uma conclusão importante deste estudo comparativo foi de que vários países estão em processo de revisão de seus modelos de gestão, pela inadequação que mostraram diante de mudanças ocorridas no contexto socioeconômico em que estão inseridos. Vimos que a tendência geral é a busca de maior equilíbrio em relação às atribuiçóes, deveres $\mathrm{e}$ responsabilidades pelo produto final entre as diversas instâncias envolvidas com a educação. Observa-se, também, preocupação com maior consistência na definiçáo da política e prática educacionais. A nosso ver, ambos os aspectos encontram-se falhos em nossos sistema educativo e, neste sentido, podem ser responsabilizados pela má qualidade do ensino e pelo malogro dos programas que visavam corrigi-lo.

A pouca participaçáo financeira e administrativa do poder central na educação brasileira fortaleceu a tendência à centralização local em 
muitos estados, como em São Paulo. Esta centralização se traduz não só nas proporçóes gigantescas que assumiu a pasta da Educação, na existência de muitas instâncias administrativas pouco articuladas, cujos papéis muitas vezes se sobrepóem mas, principalmente, na dificuldade que programas de melhoria da qualidade de ensino têm enfrentado para sua efetiva implantação. No caso do Ciclo Básico, a gestão inadequada se traduziu em uma política de Recursos Humanos incompatível com a proposta do programa, que pretendia proporcionar atendimento especializado aos alunos com maior dificuldade na alfabetização, através de duas horas diárias adicionais na escola. Entretanto, a equiparaçáo dos professores I aos de nível III inviabilizou a proposta, pois diminuiu a jornada de trabalho dos primeiros, dificultando este atendimento aos alunos, bem como a frequiência a reunióes e outras atividades programadas para o seu aprimoramento docente. Esta situaçáo só foi corrigida na Jornada Única, que estipulou a permanência de professores e alunos na escola pelo período de seis horas durante o ciclo básico.

Já os problemas enfrentados pela Jornada Única foram de ordem administrativa, como repasse de verbas e materiais, fazendo com que fosse implantado de início apenas em $\mathbf{4 0 \%}$ das escolas. Tais resultados seriam diferentes se as medidas descentralizadoras tivessem sido apenas mais rápidas e amplas.

É importante lembrar, entretanto, que as medidas tomadas até o momento limitam-se, a nosso ver, à transferência de responsabilidades para as instâncias mais próximas às escolas, como as delegacias de ensino e, no caso da pré-escola, aos municípios. Por isso, não são suficientes porque não dão autonomia à escola, tanto administrativa como financeira. Nesta perspectiva, não são cobrados resultados dos responsáveis pelo produto final. Mais, ainda - as unidades tendem, segundo diagnóstico da FUNDAP, a reproduzir em pequena escala o modelo de gestão ao qual estão submetidas: centralismo, burocracia e administração alheia às principais questóes educacionais. O privilégio das atividades-meio em detrimento das atividades-fim, em consonância com o sistema administrativo, a centralização da autoridade têm como consequiência a passividade e a falta de responsabilidade e profissionalismo dos professores. Agrava ainda mais a situação a desmotivadora remuneração destes profissionais, a ausência de um controle sobre a sua qualificaçāo, já que a metade não é concursada.

Neste sentido, a conclusão deste trabalho é a de que apenas medidas de ordem quantitativa, como um investimento realmente racional na educação, reduzindo despesas, aumentando salários e permanência da criança na escola não bastam. É preciso confiar mais na escola, dotá-la 
de maior autonomia para estabelecer seus objetivos e os meios através dos quais possa atingi-los. Para tanto, é necessário que nosso modelo de gestão seja revisado a exemplo dos países estudados, na direçáo de um maior equilíbrio de direitos, deveres e responsabilidades.

\section{Bibliografia}

ARANHA, M. L. de A. Historia da Educafulo. Editora Moderna, 1990.

BRASIL. Ministry of Education. 42: Session of the International Conference on Education. The development of educution from 1988 to 1990 - National Report. Geneva, september, 1990.

CAMPINO, A. C. Economia e Educação. Revista Faculdade de Edtucagtlo. São Paulo. 12 (1/2):5-36, jan./dez., 1986.

CARVALHO, D. Diretrizes e bases para rena reforma da educageto nacional. Escola Superior de Guerra - Departamento de Estudos, 1985.

CRUZ, O. L. Edtucagato: Indicudores Sociais. IBGE. RJ, v.1, 1981/87.

CUNHA, L. A. Educageto e Desenvolvimento Social no Brasil. Livraria Francisco Alves Editora S.A. 5? ediçăo, 1990.

ESTADO DE SÅO PAULO. Secretaria de Estado da Educação - Assessoria T́́cnica de Planejamento e Controle Educacional. Amudrio estattstico de educuguto do Estado de Sato Pauto. Centro de Informaçōes Educacionais, v.5, $n^{\circ} 1$.

ESTADO DE SĀO PAULO. Secretaria de Estado da Educação - Assessoria Téenica de Planejamento e Controle Educacional. Estrutsticas educucionatis bdsicas. Séries Históricas, Strie Estatlstica, n 1. Centro de Informaçöes Educacionais, 1978-1988.

ESTADO DE SÃO PAULO. Secretaria de Estado da Educação - Assessoria Técnica de Planejamento e Controle Educacional. Indicudores de permantincia. Rede Estadual. Strie Estatística, $n^{2}$ 1. Centro de Informaçóes Educacionais, 1984-1988.

FERRAZ, J. E. G. Andtise do sistemer educucional brasileciro. Tese apresentada para Título de Mestre, 1969.

FONDO MONETARIO INTERNACIONAL. Estattsticas financairas intermacionales. Diversos anos.

INSTITUTO DE PESQUISAS E ESTUDOS SOCIAIS. A cducapato que nos convem. IPES/GB, 1968.

LESOURNE, J. D. Education \& socitte les defis de l'an 2000. Le Monde de L'Bducation.

MINISTÉRIO DA EDUCAÇĀO E CULTURA. Ensino de primeiro e segundo grau: anualizaguto e axparssto. Brastlia, 1970.

PEREZ, J. R. A poltaica educacional no Estodo de Sato Paulo. NEPP/UNICAMP, 1990. 
ROSEMBERG, F. 2\% Grau no Brasil: cobertura, clientela e recursos. Revista de Estudos e Pesquisas em Educaģão. Cadernos de Pesquisa. Fundação Carlos Chagas, fev./68, 1989.

SANDER, B. Educafaño brasileira: valores formais e palores reais. Livraria Pioneira Editora, 1977.

SILVA, R. M. R. Crianças \& adolescentes: indicadores sociais. IBGE, RJ, v.1, 1987.

TEIXEIRA, M. C. S. Politica e administrasto de pessoal docente: um estudo sobre a Secretaria de Estado da Educafáo do Estado de São Paulo. (Estudo e Documentos) Faculdade de Educação/USP, v. 27, 1988.

VILLALOBOS, J. E. R. Diretrizes e bases da educafdo: ensino e liberdade. Biblioteca Pioneira de Ciências Sociais, 1969.

\title{
Resumo
}

Esta pesquisa teve como principal objetivo estabelecer uma comparação entre nosso sistema educacional e os dos seguintes países: Estados Unidos, França, Alemanha, Coréia, Cuba e Japão. As principais fontes de dados sobre estes países foram anuários estatísticos e relatórios. Os resultados mostraram que a efetividade do nosso sistema encontra-se abaixo da média de outros países. Medidas no sentido de reverter esta situação não podem restringir-se àquelas de ordem quantitativa. Como mostra a experiência de alguns destes países, é preciso revisar a gestão do sistema a fim de promover as mudanças necessárias.

\begin{abstract}
This research had as it's main objective establishing a comparision between our educacional system and those of the following countries: Japan, Korea, USA, Germany, France anda Cuba. The main sources of data about thesesw countries were reporte and statistical year books. The resultsshowes that our system effectuality is below the average of these contries and attempts to revert this situation shouldnot be restricted to quantitative adjustments. Some of these countries experience showed that it is also necessary to revise system's management in order to promote substantial modifications.
\end{abstract}

Maria Tereza Leme Fleuryé professora da Faculdade de Economia e Administração da USP.

Maria Isabel Leme de Mattos é professora do Instituto de Psicologia da USP.

Este estudo foi realizado atendendo a uma demanda da Secretaria da Educação do Estado de São Paulo, de setembro a dezembro de 1990. A escolha dos países a serem comparados com o Estado de São Paulo foi feita pelo próprio secretário da Educação: Prof. Carlos Estevam Martins. Participou também desta pesquisa o Prof. Andre Fischer, da FEA/USP. 